\title{
The application of intelligent information systems in hemodialysis adequacy promotion
}

\author{
Mohamad Jebraeily ${ }^{1}$, Reza Safdari ${ }^{2}$, Bahlol Rahimi ${ }^{1}$, Khadijeh Makhdoomi ${ }^{3}$, Marjan Ghazisaeidi ${ }^{*}$ \\ ${ }^{1}$ Department of Health Information Technology, School of Allied Medical Sciences, Urmia University of Medical Sciences, Urmia, Iran \\ ${ }^{2}$ Department of Health Information Management, School of Allied Medical Sciences, Tehran University of Medical Sciences, Tehran, Iran \\ ${ }^{3}$ Nephrology and Renal Transplant Research Center, Urmia University of Medical Sciences, Urmia, Iran
}

\section{A R T I C L E I N F O}

Article Type:

Review

\section{Article History:}

Received: 9 December 2016

Accepted: 9 August 2017

Published online: 6 September 2017

\section{Keywords:}

Intelligent information systems

Decision support systems

Artificial intelligence

Hemodialysis adequacy

\begin{abstract}
A B S T R A C T
Despite recent improvements in technology of dialysis machine and updated treatment protocols, hemodialysis patients suffer from a high rate of morbidity and mortality. In dialysis centers, healthcare staffs should attempt to provide reliable and efficient care in accordance with clinical guidelines. Integrating intelligent information systems in hemodialysis process have substantially reduced the medical errors rate and improved the quality and efficiency of healthcare through utilize of clinical practice guidelines and of patient information. In this review, we summarize the most important applications of intelligent information systems in hemodialysis adequacy promotion.
\end{abstract}

Implication for health policy/practice/research/medical education:

Intelligent information systems can create an excellent opportunity to nephrologists for appropriate prescriptions, hemodialysis adequacy monitoring, drug prescription, anemia management, blood pressure control and patient education. Indeed, these technologies make sure patient safety and reduce medical errors through identifying high-risk patients and timely interventions to improve health care processes

Please cite this paper as: Jebraeily M, Safdari R, Rahimi B, Makhdoomi K, Ghazisaeidi M. The application of intelligent information systems in hemodialysis adequacy promotion. J Renal Inj Prev. 2018;7(2):64-68. DOI: 10.15171/jrip.2018.16.

\section{Introduction}

End-stage renal disease (ESRD) has been recognized as a worldwide public health problem by increasing rapidly rates of incidence and prevalence (1). Today, it is estimated to be more than 3 million ESRD patients worldwide (2). ESRD is primarily caused by diabetes, hypertension, and glomerulonephritis (3).

Hemodialysis (HD) is the most common treatment of ESRD patients. It is a blood-filtering artificial technique aimed to remove toxins and water from patient's body (4). Despite recent improvements in dialysis machine technology and updated treatment protocols, HD patients suffer from a high rate of morbidity and mortality $(5,6)$. The long-term property and repetitive process of dialysis treatment generate returning data which is collected to meet information needs of healthcare providers $(7,8)$. In dialysis centers, healthcare staffs should attempt to provide reliable and efficient care in accordance with clinical guidelines (9). The use of accurate and reliable data generated online during dialysis can behelpful in evaluating the effectiveness of delivered dialysis (10-12). Information systems provide crucial evidence necessary for decisionmaking in health care (13). Through the implementation of a robust quality information system, available raw data could be turned into effective information, leading to new knowledge that may improve patients care (12-14). The information systems are facilitated to assessment of patient health status and identification of high-risk 
patients for targeting for either preventative or therapeutic purposes $(9,11,13)$. Integrating intelligent information systems in HD process have substantially reduced medical error rate and improved the quality and efficiency of heath care through utilize of clinical practice guidelines and patient information $(15,16)$. The most dialysis centers spent their effort in maintaining and manipulating data related to dialysis through the design and implementation of information systems (9-12).

Giving these into account, we aimed to answer; where and how can intelligent information systems apply for the promotion of HD adequacy? And, what lessons can we learn for our healthcare system?

\section{Materials and Methods}

We conducted a literature search on three databases including PubMed, EMBASE, and Cochrane Library which were investigated from 2005 through May 2015. The selection procedure for the above-mentioned databases was based on two conditions recommended in relevant texts $(17,18)$. The search was performed using a combination of the following terms; intelligent information systems, decision support systems, artificial intelligence, expert systems, and HD adequacy. To be included in the review, the language of the intended paper must be English. Figure 1 presents a process of selecting papers for the review in detail. Finally, 35 reviewed articles met the inclusion criteria.

\section{Prescription of hemodialysis treatment}

$\mathrm{HD}$ is a prescribed treatment procedure. It is very important to conduct regularly to eliminate uremic toxins from the patient's body $(7,9)$. The removing a suitable volume, waste materials, creating a fluid homeostasis and will reinforce quality of life $(19,20)$. It is necessary for nephrologist to order a treatment program based on the fundamental variables for each patient such as; dialysis frequency, dialysis session length, dry weight, blood flow $(\mathrm{Qb})$, dialysate flow $(\mathrm{Qd})$, dialyzer type, ultrafiltration and heparin dosage $(7,9,15,20)$.

There are several methods to measure the dose of dialysis, among which, the target $\mathrm{Kt} / \mathrm{V}$ is the most highly applied one (8). In target $\mathrm{Kt} / \mathrm{V}, K$ is the clearance of the dialyzer, $t$ is the time of the dialysis treatment, and $V$ is the volume of urea distribution. Intelligence systems applied neural networks for solution of difficult issues (19-21). Intelligence systems also perform the complicated calculation of HD dose prescription and rational advice for determination of dialyzer type, blood flow rate, and number of hours of dialysis/week. These data may be readily accessible and useful to qualified users in operational dialysis centers (7-10).

\section{Monitoring of hemodialysis adequacy}

Nurses should carefully apply the treatment plan to each dialysis session (6). The concordance between the

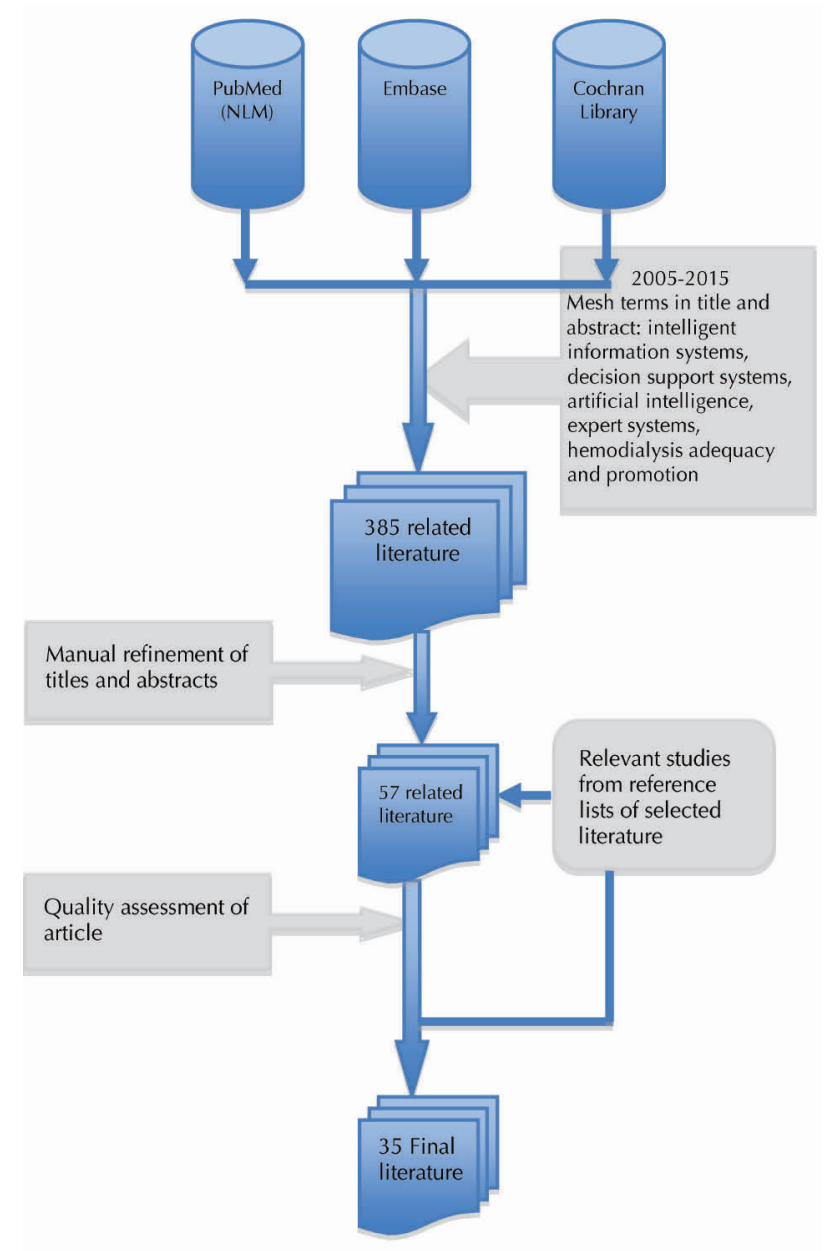

Figure 1. Flowchart of selecting studies for the review.

prescribed dose and really delivered dialysis should serve as key performance to improve quality of $\operatorname{HD}(22,23)$. The issue of noncompliance may help to prevent or to discover care management complication, to find administrative failure and to reform treatment plans (7). The urea reduction ratio (URR) and $\mathrm{Kt} / \mathrm{V}$ are a mathematical description equaling the intake of protein and removal of urea during dialysis (19-21). These indicators can easily be monitored during each treatment course using the dialysis information system that to review both procedures and outcomes $(23,24)$. The National Kidney Foundation (NKF) approves a URR greater than $65 \%$ and a Kt/V greater than 1.2 for HD adequacy (4).

Bellazzi et al implemented an automated system that compared delivered treatment with prescribed treatment and detected failures-to-adhere and alerted to the caregivers (7).

\section{Anemia management}

The iron deficiency is routine in dialysis patients as blood loss generally occurs during the treatment period $(25,26)$. In recent years dialysis centers tried to create an anemia management approach to make better clinical outcomes and quality of life among HD patients (27). Presence 
of drug interaction, dialysis treatment, and patient condition complicates the suitable treatment of anemia. The result of recent studies showed that application of the knowledge-based systems in recommendation dosage of erythropoietin would increase the hemoglobin level to the proper range (25-27).

Raghavan et al developed a decision support system for generation simplified anemia rule (12). In other research Martín-Guerrero et al used a reinforcement learning approach for anemia management in HD patients (28).

\section{Patient education}

Patients' education has been emerged as an important component in HD patients. Following the medical instructions, altering lifestyle and modifying their dietary habits are some items in patients' education. The result of researches indicated that patients' education developed self-care and self-management behaviors (29-31).

Studies reported patients' education in HD is applicable through smartphone applications and text-messaging is convenient and effective and remote monitoring of patients $(32,33)$.

Interactive multimedia software is already playing a key and unique role in the process of patient education. This technology can be used as an appealing tool to motivate patients to learn self-management and self-care (30). Information system should be developed to promote the interaction between patients and physicians for effective management of patients' condition (31-34).

\section{Drug prescription}

The incidence and severity of adverse drug events in HD patients has been a focus of recent attention. More significantly, most of these adverse drug events can be prevented by administration of appropriate dosage of drugs according to proportion of kidney function $(35,36)$. Clinical decision support systems (CDSSs) are designed to improve drug prescribing. CDSS can alert automatically through a computer if a prescribed medication dose is excessive $(37,38)$. These systems suggest drug dosing which could be based on progression of kidney failure or in response to serum drug concentrations or other clinical parameters. These CDSSs enhance health care outcomes usually through dosing guidance and assessment of drugallergy to modify inappropriate drugs (36-39). Intelligent systems provided the necessary framework to reduce kidney-related drug prescribing errors $(39,40)$.

\section{Blood pressure control}

Hypertension and continuous volume overload are the problems that are mostly observed in HD patients. The results of surveys showed that $50 \%$ to $90 \%$ of patients on dialysis have hypertension $(41,42)$. In these patients, the expansion of dialysate sodium prescription is a critical factor to achieve the sodium balance as well as easy to the blood pressure control (42-44). Gabutti et al recommended a neural network for continuous monitoring of blood pressure in dialysis patients. They showed this network has high ability to predict blood pressure and to estimate the situation of patient (45).

\section{Hemodialysis information management}

Due to the intricacy of process of dialysis and the need for monitoring the adequacy of dialysis, all information should be documented, analyzed, reserved and retrievable effectively (6). The effective management of HD data would be greatly facilitated by development and usage of information systems that are capable of synchronously gathering and processing of HD clinical data in the point of care (7-9).

Timely access to the information of the treatment which is received by patient with comparison to the ordered treatment will enable the nephrologists to appropriate handling and earning an optimum dialysis $(8,10)$. Indeed, information systems help staffs of dialysis center to complete their documents, reporting, decision-making processes and finally to evaluate the quality of care (11, 12,24).

\section{Conclusion}

Intelligent information systems can create an excellent opportunity to nephrologists for appropriate prescriptions, HD adequacy monitoring, drug prescription, identification of high-risk patients and patient education. Recent researches reveal positive outcomes when intelligent information systems are applied in HD adequacy promotion. Therefore, it seems necessary to supply the crucial infrastructures for implementation of such systems. It is proposed that set up several courses through e-learning to the empowerment of healthcare providers in dialysis centers for employment of intelligent information systems.

\section{Authors' contribution}

Primary draft by MJ, KM and BR. Editing the final manuscript by GM and RS. All authors read and signed the final manuscript.

\section{Conflicts of interest}

The authors declared no competing interests.

\section{Ethical considerations}

Ethical issues (including plagiarism, data fabrication, double publication) have been completely observed by the authors.

\section{Funding/Support}

None.

\section{References}

1. Himmelfarb J, Ikizler TA. Hemodialysis. N Engl J Med. 2010;363:1833-45. doi: 10.1056/NEJMra0902710. 
2. Eckardt KU, Coresh J, Devuyst O, Johnson RJ, Kottgen A, Levey AS, et al. Evolving importance of kidney disease: from subspecialty to global health burden. Lancet. 2013;382:15869. doi: 10.1016/s0140-6736(13)60439-0.

3. Hering D, Mahfoud F, Walton AS, Krum H, Lambert GW, Lambert EA, et al. Renal denervation in moderate to severe CKD. J Am Soc Nephrol. 2012;23:1250-7. doi: 10.1681/ asn.2011111062.

4. Daugirdas JT. Prescribing and monitoring hemodialysis in a 3-4 x/week setting. Hemodial Int. 2008;12:215-20. doi: 10.1111/j.1542-4758.2008.00255.x.

5. Chang J, Ronco C, Rosner MH. Computerized decision support systems: improving patient safety in nephrology. Nat Rev Nephrol. 2011;7:348-55. doi: 10.1038/nrneph.2011.50.

6. Jebraeily M, Ghazisaeidi M, Safdari R, Makhdoomi K, Rahimi B. Hemodialysis Adequacy Monitoring Information System: Minimum Data Set and Capabilities Required. Acta Inform Med. 2015;23:239-42. doi: 10.5455/ aim.2015.23.239-242.

7. Bellazzi R, Sacchi L, Caffi E, de Vincenzi A, Nai M, Manicone F, et al. Implementation of an automated system for monitoring adherence to hemodialysis treatment: a report of seven years of experience. Int J Med Inform. 2012;81:320-31. doi: 10.1016/j.ijmedinf.2012.01.007.

8. Soetomo RD. A Knowledge-based Hemodialysis HealthCare Information System with Analytical Functions of Temporal Assessments for Monitoring and Treatment Plan of Hemodialysis Patient. The 14th Industrial Electronics Seminar, Surabaya, Indonesia; 2012.

9. Azar AT. A novel system for haemodialysis efficiency monitoring. Int J Healthc Technol Manag. 2011;12:132-67. doi: 10.1504/IJHTM.2011.039626.

10. Xie F, Zhang D, Wu J, Zhang Y, Yang Q, Sun X, et al. Design and implementation of the first nationwide, web-based Chinese Renal Data System (CNRDS). BMC Med Inform Decis Mak. 2012;12:11. doi: 10.1186/1472-6947-12-11.

11. Yao ZM, Bai LJ, Guo FS. Design and Implementation of Hemodialysis Intelligent Management System. Applied Mechanics and Materials. 2012;121-126:1804-8.

12. Raghavan SR, Ladik V, Meyer KB. Developing decision support for dialysis treatment of chronic kidney failure. IEEE Trans Inf Technol Biomed. 2005;9:229-38.

13. Safdari R, Ghazisaeidi M, Jebraeily M. Electronic health records: critical success factors in implementation. Acta Inform Med. 2015;23:102-4. doi: 10.5455/aim.2015.23.102104.

14. Pollak VE, Lorch JA. Effect of electronic patient record use on mortality in End Stage Renal Disease, a model chronic disease: retrospective analysis of 9 years of prospectively collected data. BMC Med Inform Decis Mak. 2007;7:38. doi: 10.1186/1472-6947-7-38.

15. Jani YH, Ghaleb MA, Marks SD, Cope J, Barber N, Wong IC. Electronic prescribing reduced prescribing errors in a pediatric renal outpatient clinic. J Pediatr. 2008;152:214-8. doi: 10.1016/j.jpeds.2007.09.046.

16. Javed F, Savkin AV, Chan GS, Mackie JD, Lovell NH. Recent advances in the monitoring and control of haemodynamic variables during haemodialysis: a review. Physiol Meas. 2012;33:R1-r31. doi: 10.1088/0967-3334/33/1/r1.

17. Montori VM, Wilczynski NL, Morgan D, Haynes RB. Optimal search strategies for retrieving systematic reviews from Medline: analytical survey. BMJ. 2005;330:68. doi: 10.1136/bmj.38336.804167.47.
18. Shuster JJ. Review: Cochrane handbook for systematic reviews for interventions, Version 5.1.0, published 3/2011. Julian P.T. Higgins and Sally Green, Editors. Res Synth Methods. 2011;2:126-30. doi: 10.1002/jrsm.38.

19. Baurmeister U, Vienken J, Ward RA. Should dialysis modalities be designed to remove specific uremic toxins? Semin Dial. 2009;22:454-7. doi: 10.1111/j.1525139X.2009.00599.x.

20. Locatelli F, Buoncristiani U, Canaud B, Kohler H, Petitclerc T, Zucchelli P. Dialysis dose and frequency. Nephrol Dial Transplant. 2005;20:285-96. doi: 10.1093/ndt/gfh550.

21. Gotch F. The basic, quantifiable parameter of dialysis prescription is $\mathrm{Kt} / \mathrm{V}$ urea; treatment time is determined by the ultrafiltration requirement; all three parameters are of equal importance. Blood Purif. 2007;25:18-26. doi: 10.1159/000096392.

22. Azar AT. Adaptive network based on fuzzy inference system for equilibrated urea concentration prediction. Comput Methods Programs Biomed. 2013;111:578-91. doi: 10.1016/j.cmpb.2013.05.012.

23. Di Noia T, Ostuni VC, Pesce F, Binetti G, Naso D, Schena FP, et al. An end stage kidney disease predictor based on an artificial neural networks ensemble. Expert Syst Appl. 2013;40:4438-45. doi: 10.1016/j.eswa.2013.01.046.

24. Chen YS, Cheng CH. Application of rough set classifiers for determining hemodialysis adequacy in ESRD patients. Knowl Inf Syst. 2013;34:453-482.

25. Gaweda AE, Jacobs AA, Aronoff GR, Brier ME. Model predictive control of erythropoietin administration in the anemia of ESRD. Am J Kidney Dis. 2008;51:71-9. doi: 10.1053/j.ajkd.2007.10.003.

26. Unger EF, Thompson AM, Blank MJ, Temple R. Erythropoiesis-stimulating agents--time for a reevaluation. N Engl J Med. 2010;362:189-92. doi: 10.1056/ NEJMp0912328.

27. Will EJ, Richardson D, Tolman C, Bartlett C. Development and exploitation of a clinical decision support system for the management of renal anaemia. Nephrol Dial Transplant. 2007;22 Suppl 4:iv31-iv6. doi: 10.1093/ndt/gfm163.

28. Martín-Guerrero JD, Gomez F, Soria-Olivas E, Schmidhuber J, Climente-Martí M, Jiménez-Torres NV. A reinforcement learning approach for individualizing erythropoietin dosages in hemodialysis patients. Expert Syst Appl. 2009;36:9737-42. doi: 10.1016/j.eswa.2009.02.041.

29. Kim Y, Evangelista LS. Relationship between illness perceptions, treatment adherence, and clinical outcomes in patients on maintenance hemodialysis. Nephrol Nurs J. 2010;37:271-80.

30. Jebraeily M, Rahimi B, Makhdoomi KF. Patient education: a study on the present situation and factors affecting success of patient education in hemodialysis. Hormozgan Medical Journal. 2016;20:250-6.

31. Logan AG. Transforming hypertension management using mobile health technology for telemonitoring and self-care support. Can J Cardiol. 2013;29:579-85. doi: 10.1016/j. cjca.2013.02.024.

32. Dageforde LA, Cavanaugh KL. Health literacy: emerging evidence and applications in kidney disease care. Adv Chronic Kidney Dis. 2013;20:311-9. doi: 10.1053/j. ackd.2013.04.005.

33. Diamantidis CJ, Becker S. Health information technology (IT) to improve the care of patients with chronic kidney disease (CKD). BMC Nephrol. 2014;15:7. doi: 
10.1186/1471-2369-15-7.

34. Bennett PN, Jaeschke S, Sinclair PM, Kerr PG, Holt S, Schoch $\mathrm{M}$, et al. Increasing home dialysis knowledge through a web-based e-learning program. Nephrology (Carlton). 2014;19:345-51. doi: 10.1111/nep.12231.

35. Cardone KE, Bacchus S, Assimon MM, Pai AB, Manley HJ. Medication-related problems in CKD. Adv Chronic Kidney Dis. 2010;17:404-12. doi: 10.1053/j.ackd.2010.06.004.

36. Niedrig D, Krattinger R, Jodicke A, Gott C, Bucklar G, Russmann S. Development, implementation and outcome analysis of semi-automated alerts for metformin dose adjustment in hospitalized patients with renal impairment. Pharmacoepidemiol Drug Saf. 2016;25:1204-9. doi: 10.1002/pds.4062.

37. Field TS, Rochon P, Lee M, Gavendo L, Baril JL, Gurwitz JH. Computerized clinical decision support during medication ordering for long-term care residents with renal insufficiency. J Am Med Inform Assoc. 2009;16:480-5. doi: 10.1197/jamia.M2981.

38. Miskulin DC, Weiner DE, Tighiouart H, Ladik V, Servilla $\mathrm{K}$, Zager PG, et al. Computerized decision support for EPO dosing in hemodialysis patients. Am J Kidney Dis. 2009;54:1081-8. doi: 10.1053/j.ajkd.2009.07.010.

39. McCoy AB, Waitman LR, Gadd CS, Danciu I, Smith JP, Lewis JB, et al. A computerized provider order entry intervention for medication safety during acute kidney injury: a quality improvement report. Am J Kidney Dis.
2010;56:832-41. doi: 10.1053/j.ajkd.2010.05.024.

40. Prajapati A, Ganguly B. Appropriateness of drug dose and frequency in patients with renal dysfunction in a tertiary care hospital: A cross-sectional study. J Pharm Bioallied Sci. 2013;5:136-40. doi: 10.4103/0975-7406.111829.

41. Santos SF, Peixoto AJ. Revisiting the dialysate sodium prescription as a tool for better blood pressure and interdialytic weight gain management in hemodialysis patients. Clin J Am Soc Nephrol. 2008;3:522-30. doi: 10.2215/cjn.03360807.

42. Santos SF, Peixoto AJ. Hypertension in dialysis. Curr Opin Nephrol Hypertens. 2005;14:111-8.

43. Agarwal R. Management of hypertension in hemodialysis patients. Hemodial Int. 2006;10:241-8. doi: 10.1111/j.15424758.2006.00102.x.

44. Cornalba C, Bellazzi RG, Bellazzi R. Building a normative decision support system for clinical and operational risk management in hemodialysis. IEEE Trans Inf Technol Biomed. 2008;12:678-86. doi: 10.1109/titb.2008.920781.

45. Gabutti L, Vadilonga D, Mombelli G, Burnier M, Marone C. Artificial neural networks improve the prediction of $\mathrm{Kt} / \mathrm{V}$, follow-up dietary protein intake and hypotension risk in haemodialysis patients. Nephrol Dial Transplant. 2004;19:1204-11. doi: 10.1093/ndt/gfh084.

Copyright $\odot 2018$ The Author(s); Published by Nickan Research Institute. This is an open-access article distributed under the terms of the Creative Commons Attribution License (http://creativecommons.org/licenses/by/4.0), which permits unrestricted use, distribution, and reproduction in any medium, provided the original work is properly cited. 